\title{
Diffusion Coefficients of Copper Chloride in Aqueous Solutions at 298.15 K and 310.15 K
}

\author{
Ana C. F. Ribeiro, ${ }^{*, \dagger}$ Miguel A. Esteso, ${ }^{\ddagger}$ Victor M. M. Lobo, ${ }^{\dagger}$ Artur J. M. Valente, ${ }^{\dagger}$ \\ Susana M. N. Simões, ${ }^{\dagger}$ Abilio J. F. N. Sobral, ${ }^{\dagger}$ and Hugh D. Burrows ${ }^{\dagger}$
}

Department of Chemistry, University of Coimbra, 3004-535 Coimbra, Portugal, and Department of Physical Chemistry, University of La Laguna, Tenerife, Canary Islands

\begin{abstract}
Mutual diffusion coefficients (interdiffusion coefficients) and molar conductivities have been measured for copper(II) chloride in water at $298.15 \mathrm{~K}$ and $310.15 \mathrm{~K}$ at concentrations between $0.005 \mathrm{~mol} \cdot \mathrm{dm}^{-3}$ and $0.05 \mathrm{~mol} \cdot \mathrm{dm}^{-3}$. The diffusion coefficients were measured using a conductometric cell. The experimental data are discussed on the basis of the Onsager-Fuoss model. The Nernst diffusion coefficients derived from diffusion $\left(1.297 \times 10^{-9}\right.$ and $\left.1.690 \times 10^{-9}\right) \mathrm{m}^{2} \cdot \mathrm{s}^{-1}$ and from conductance $\left(1.282 \times 10^{-9}\right.$ and $1.663 \times$ $\left.10^{-9}\right) \mathrm{m}^{2} \cdot \mathrm{s}^{-1}$ at two temperatures $(298.15 \mathrm{~K}$ and $310.15 \mathrm{~K}$, respectively) are in good agreement.
\end{abstract}

\section{Introduction}

The knowledge of electrolytes diffusion data is of great interest not only for fundamental purposes but also in order to be used in many technical fields as, for example, for corrosion studies. Our research group is especially interested in dental restoration research and therefore in obtaining data for ionic systems involved in the dental damage processes into the oral cavity, ${ }^{1-6}$ which are necessary but not available in the literature. The knowledge of these data is essential to adequately understand and solve some of the problems derived from the deterioration of the dental amalgams implanted, as a consequence of both the wear-and-tear and the mouth digestion processes.

Because up to now, data on differential mutual diffusion coefficients, $D$ (interdiffusion coefficients), for $\mathrm{Cu}$ (II) salts appear not to be published, ${ }^{7}$ we have determined those related to $\mathrm{CuCl}_{2}$ aqueous solutions in the concentration range from $(0.005$ to 0.05$) \mathrm{mol} \cdot \mathrm{dm}^{-3}$, which is the most probable one in the oral cavity. The experimental technique used was the conductometric one by using an open-ended capillary cell. ${ }^{8-24}$ The results thus obtained were analyzed with the help of the Onsager-Fuoss equations ${ }^{25-28}$ by considering that copper(II) species may be present either as under-hydrolyzed forms or as complexes. ${ }^{29,30}$ These studies are complemented by conductance measurements, having also in mind that they can contribute to the understanding of the diffusion of this electrolyte in solution.

\section{Experimental Section}

Reagents. Copper(II) chloride dehydrate (Riedel-deHaen, Seelze, Germany, pro analysi >99 \%) was used without further purification. The concentration of all aqueous $\mathrm{CuCl}_{2}$ solutions was obtained by titration.

The solutions for the diffusion measurements were prepared in calibrated volumetric flasks using bi-distilled water. The solutions were freshly prepared and de-aerated for about $30 \mathrm{~min}$ before each set of runs.

* Corresponding author. E-mail: anacfrib@ci.uc.pt. Tel: +351-239-

854460. Fax: +351-239-827703.

$\dagger$ University of Coimbra.

¥ University of La Laguna.
Solutions used in conductance measurements were prepared by using Millipore water $\left\{\kappa=(0.7\right.$ to 0.9$) \times 10^{-4}$ $\left.\mathrm{S} \cdot \mathrm{m}^{-1}\right\}$. All solutions were freshly prepared just before each experiment.

Diffusion Measurements. An open-ended capillary cell, which has been used to obtain mutual diffusion coefficients for a wide variety of electrolytes, ${ }^{8,9}$ is described in great detail in previous papers. ${ }^{8-24}$ Basically, this consists of two vertical capillaries, each closed at one end by a platinum electrode, and positioned one above the other with the open ends separated by a distance of about $14 \mathrm{~mm}$. The upper and lower tubes, initially filled with solutions of concentrations $0.75 c$ and $1.25 c$, respectively, are surrounded with a solution of concentration $c$. This ambient solution is contained in a glass tank $(200 \times 140 \times 60) \mathrm{mm}$ immersed in a thermostated bath at $25^{\circ} \mathrm{C}$. Perspex sheets divide the tank internally, and a glass stirrer creates a slow lateral flow of ambient solution across the open ends of the capillaries. Experimental conditions are such that the concentration at each of the open ends is equal to the ambient solution value $c$, that is, the physical length of the capillary tube coincides with the diffusion path. This means that the required boundary conditions described in the literature $^{8}$ to solve Fick's second law of diffusion are applicable. Therefore, the so-called $\Delta l$ effect $^{8}$ is reduced to negligible proportions. In our manually operated apparatus, diffusion is followed by measuring the ratio $w=$ $R_{\mathrm{t}} / R_{\mathrm{b}}$ of resistances $R_{\mathrm{t}}$ and $R_{\mathrm{b}}$ of the upper and lower tubes by an alternating current transformer bridge. In our automatic apparatus, $w$ is measured by a Solartron digital voltmeter (DVM) 7061 with 6 1/2 digits. A power source (Bradley Electronic model 232) supplies a $30 \mathrm{~V}$ sinusoidal signal at $4 \mathrm{kHz}$ (stable to within $0.1 \mathrm{mV}$ ) to a potential divider that applies a $250 \mathrm{mV}$ signal to the platinum electrodes in the top and bottom capillaries. By measuring the voltages $V^{\prime}$ and $V^{\prime \prime}$ from top and bottom electrodes to a central electrode at ground potential in a fraction of a second, the DVM calculates $w$.

To measure the differential diffusion coefficient $(D)$ at a given concentration $(c)$, the bulk solution of concentration 
Table 1. Diffusion Coefficients $(D)^{a}$ of $\mathrm{CuCl}_{2}$ in Aqueous Solutions at Various Concentrations (c) and Different Temperatures and the Standard Deviations of the Means (SD) ${ }^{b}$

\begin{tabular}{|c|c|c|c|c|}
\hline \multirow[b]{2}{*}{$c$} & \multicolumn{2}{|c|}{$T=298.15 \mathrm{~K}$} & \multicolumn{2}{|c|}{$T=310.15 \mathrm{~K}$} \\
\hline & $D$ & SD & $D$ & SD \\
\hline $\mathrm{mol} \cdot \mathrm{dm}^{-3}$ & $10^{-9} \mathrm{~m}^{2} \cdot \mathrm{s}^{-1}$ & $10^{-9} \mathrm{~m}^{2} \cdot \mathrm{s}^{-1}$ & $10^{-9} \mathrm{~m}^{2} \cdot \mathrm{s}^{-1}$ & $10^{-9} \mathrm{~m}^{2} \cdot \mathrm{s}^{-1}$ \\
\hline 0.005 & 1.235 & 0.001 & 1.660 & 0.010 \\
\hline 0.008 & 1.208 & 0.001 & 1.640 & 0.011 \\
\hline 0.01 & 1.199 & 0.001 & 1.630 & 0.010 \\
\hline 0.02 & 1.128 & 0.002 & 1.580 & 0.010 \\
\hline 0.03 & 1.121 & 0.001 & 1.544 & 0.010 \\
\hline 0.05 & 1.120 & 0.017 & 1.500 & 0.011 \\
\hline
\end{tabular}

${ }^{a} D$ is the mean diffusion coefficient for three experiments. ${ }^{b} \mathrm{SD}$ is the standard deviation of that mean.

$c$ is prepared by mixing $1 \mathrm{~L}$ of "top" solution with $1 \mathrm{~L}$ of "bottom" solution, measured accurately. The glass tank and the two capillaries are filled with $c$ solution, immersed in the thermostat, and allowed to come to thermal equilibrium. The resistance ratio $w=w_{\infty}$ measured under these conditions (with solutions in both capillaries at concentration $c$ ) accurately gives the quantity $\tau_{\infty}=10^{4} /\left(1+w_{\infty}\right)$

The capillaries are filled with the "top" and "bottom" solutions, which are then allowed to diffuse into the "bulk" solution. Resistance ratio readings are taken at various recorded times, beginning $1000 \mathrm{~min}$ after the start of the experiment, to determine the quantity $\tau=10^{4} /(1+w)$ as $\tau$ approaches $\tau_{\infty}$. The diffusion coefficient is evaluated using a linear least-squares procedure to fit the data; finally, an iterative process is applied using 20 terms of the expansion series of Fick's second law for the present boundary conditions. The theory developed for the cell has been described previously. ${ }^{8}$

Conductance Measurements. Solution electrical resistances were measured with a Wayne-Kerr model 4265 automatic LCR meter at $1 \mathrm{kHz}$. A Shedlovsky-type conductance cell with a cell constant of around $0.8465 \mathrm{~cm}^{-1}$ was used. ${ }^{22}$ Cell constants were determined from measurements with $\mathrm{KCl}$ (reagent grade, recrystallized, and dried) using the procedure and data of Barthel et al. ${ }^{31}$ Measurements were taken at $(25.00 \pm 0.01){ }^{\circ} \mathrm{C}$ in a Grant thermostat bath. Solutions were always used within $12 \mathrm{~h}$ of preparation. In a typical experiment, $100 \mathrm{~mL}$ of water was placed in the conductivity cell; then, aliquots of the copper(II) chloride solution were added in a stepwise manner using a micropipet Metrohm 765 dosimate. The conductance of the solution was measured after each addition and corresponds to the average of three ionic conductances, obtained through homemade software.

pH Measurements. $\mathrm{pH}$ measurements were carried out with a Radiometer $\mathrm{pH}$ meter PHM 240 with an Ingold $\mathrm{U} 457-\mathrm{K} 7 \mathrm{pH}$ conjugated electrode; $\mathrm{pH}$ was measured in fresh solutions, and the electrode was calibrated immediately before each experimental set of solutions using IUPAC-recommended pH 2 and 4 buffers. From pH meter calibration a zero $\mathrm{pH}$ of $6.897 \pm 0.030$ and sensitivity higher than $98.7 \%$ were obtained.

Visible Spectroscopy. Visible spectra of $\mathrm{CuCl}_{2}$ solutions (0.005 to 0.1$) \mathrm{mol} \cdot \mathrm{dm}^{-3}$ were obtained using a spectrophotometer Jasco V-530; the spectra were obtained between (800 and 400) $\mathrm{nm}$ with a bandwidth of $0.5 \mathrm{~nm}$.

\section{Results and Discussion}

Mutual diffusion coefficients $(D)$ of $\mathrm{CuCl}_{2}$ in aqueous solutions at $298.15 \mathrm{~K}$ and $310.15 \mathrm{~K}$ are shown in Table 1 ,
Table 2. Fitting Coefficients $\left(a_{0}-a_{2}\right)$ of the Polynomial Equation $\left[D /\left(\mathbf{m}^{2} \cdot \mathbf{s}^{-1}\right)=a_{0}+a_{1}\left(\mathrm{c} / \mathbf{m o l} \cdot \mathbf{d m}^{-3}\right)+a_{2}(c /\right.$ mol $\left.\left.\cdot \mathrm{dm}^{-3}\right)\right]^{2}$ to the Mutual Differential Diffusion Coefficients for Copper Chloride in Aqueous Solutions at 298.15 K and 310.15 $\mathrm{K}^{a}$

\begin{tabular}{ccccc}
\hline$T / \mathrm{K}$ & $a_{0} \cdot 10^{9}$ & \multicolumn{1}{c}{$a_{1} \cdot 10^{9}$} & $a_{2} \cdot 10^{9}$ & $R^{2 b}$ \\
\hline 298.15 & 1.297 & -12.81 & 230.4 & 0.991 \\
310.15 & 1.690 & -6.58 & 55.62 & 0.999
\end{tabular}

${ }^{a}$ These equations were fitted to experimental data, except for $c=0.05 \mathrm{~mol} \cdot \mathrm{dm}^{-3}$ at $298.15 \mathrm{~K}$ (see Table 1$){ }^{b}$ See Experimental Section.

where $D$ is the mean value of, at least, three independent measurements. The standard deviations of the means are shown in Table 1. Previous papers reporting data obtained with this conductometric cell support our view that the inaccuracy of our results should not be much larger than the imprecision. That is, we believe that our uncertainty is not much larger than (1 to 3 ) \%. For the purposes of this study, it was not necessary to extend the limits in concentration beyond those indicated in Table 1 .

The following polynomial in $c$ was used to fit the data by a least-squares procedure:

$$
D=a_{0}+a_{1} c+a_{2} c^{2}
$$

where the coefficients $a_{0}, a_{1}$, and $a_{2}$ are adjustable parameters. Table 2 shows the coefficients $a_{0}$ to $a_{2}$ of eq 1 . These may be used to calculate values of diffusion coefficients at specified concentrations within the range of the experimental data shown in Table 1 . The goodness of the fit (obtained with a confidence interval of $98 \%$ ) can be assessed by the excellent correlation coefficients $\left(R^{2}\right)$ and the low standard deviation $(<1 \%)$.

$\mathrm{pH}$ measurements were made on some of the copper chloride solutions to assist interpretation of these results. For $0.005 \mathrm{~mol} \cdot \mathrm{dm}^{-3} \leq c \leq 0.05 \mathrm{~mol} \cdot \mathrm{dm}^{-3}$ and $T=298.15$ $\mathrm{K}$, the $\mathrm{pH}$ values were in the range $4.4 \leq \mathrm{pH} \leq 5.4$, respectively, due to hydrolysis. (The $\mathrm{pH}$ decreased when the concentration increased.) Visible spectra of $\mathrm{CuCl}_{2}$ solutions show that, over the concentration range studied, no alteration in the absorption maximum was obtained and the Beer-Lambert law was obeyed. Therefore, we may conclude that there is no change in the main complex species present in $\mathrm{CuCl}_{2}$ aqueous solutions under these conditions.

To understand the transport process of this electrolyte in aqueous solutions, as a first approach the experimental mutual diffusion coefficients at $298.15 \mathrm{~K}$ were compared with those estimated by using the Onsager-Fuoss equation suitable for dilute solutions [eq 2 (Table 3)]

$$
D=\bar{M}\left(\frac{\left|z_{1}\right|+\left|z_{2}\right|}{\left|z_{1} z_{2}\right|}\right) \frac{R T}{c}\left(1+c \frac{\partial \ln y_{ \pm}}{\partial c}\right)
$$

where $D$ is the mutual diffusion coefficient of the electrolyte in $\mathrm{m}^{2} \cdot \mathrm{s}^{-1} ; R$ is the gas constant in $\mathrm{J} \cdot \mathrm{mol}^{-1} \cdot \mathrm{K}^{-1} ; T$ is the absolute temperature; $z_{1}$ and $z_{2}$ are the algebraic valences of a cation and of an anion, respectively; the last term in parentheses is the activity factor, with $y_{ \pm}$being the mean molar activity coefficient; $c$ is the concentration in $\mathrm{mol} \cdot \mathrm{m}^{-3}$; and $\bar{M}$, in $\mathrm{mol}^{2} \cdot \mathrm{s} \cdot \mathrm{m}^{-3} \cdot \mathrm{kg}^{-1}$, is given by

$$
\bar{M}=\frac{1}{N_{\mathrm{A}}^{2} e_{0}^{2}}\left(\frac{\lambda_{1}^{0} \lambda_{2}^{0}}{v_{2}\left|z_{2}\right| \lambda_{1}^{0}+v_{1}\left|z_{1}\right| \lambda_{2}^{0}}\right) c+\overline{\Delta M^{\prime}}+\Delta \overline{M^{\prime \prime}}
$$

In eq 3, the first- and second-order electrophoretic terms 
1988 Journal of Chemical and Engineering Data, Vol. 50, No. 6, 2005

Table 3. Diffusion Coefficients of Copper Chloride Calculated from Onsager-Fuoss Theory $\left(D_{\mathrm{OF}}\right)$ at $298.15 \mathrm{~K}^{26,28}$

\begin{tabular}{|c|c|c|c|c|c|c|}
\hline$\frac{\mathrm{c}}{\left(\mathrm{mol} \cdot \mathrm{dm}^{-3}\right)}$ & $\frac{D_{\mathrm{OF}}^{\prime}}{\left(10^{-9} \mathrm{~m}^{2} \cdot \mathrm{s}^{-1}\right)^{a}}$ & $\frac{\Delta D / D_{\mathrm{OF}}^{\prime}}{\%^{b}}$ & $\frac{D_{\mathrm{OF}}^{\prime \prime}}{\left(10^{-9} \mathrm{~m}^{2} \cdot \mathrm{s}^{-1}\right)^{c}}$ & $\frac{\Delta D / D^{\prime \prime} \mathrm{OF}}{\%^{b}}$ & $\frac{D^{\prime \prime \prime}{ }_{\mathrm{OF}}}{\left(10^{-9} \mathrm{~m}^{2} \cdot \mathrm{s}^{-1}\right)^{d}}$ & $\frac{\Delta D / D^{\prime \prime \prime} \mathrm{OF}}{\%^{b}}$ \\
\hline 0.000 & 1.298 & $-0.08^{e}$ & 1.298 & $-0.08^{e}$ & 1.298 & $-0.08^{e}$ \\
\hline 0.005 & 1.202 & +2.7 & 1.205 & +2.4 & 1.205 & +2.4 \\
\hline 0.008 & 1.187 & +1.8 & 1.190 & +1.5 & 1.195 & +1.1 \\
\hline 0.010 & 1.180 & +1.6 & 1.185 & +1.2 & 1.190 & +0.8 \\
\hline 0.020 & 1.163 & -3.0 & 1.164 & -3.1 & 1.177 & $-4,2$ \\
\hline 0.030 & 1.158 & -3.2 & 1.159 & -3.3 & 1.175 & -4.6 \\
\hline 0.050 & 1.150 & -2.6 & 1.153 & -2.9 & 1.172 & -4.6 \\
\hline
\end{tabular}

${ }^{a} a=2.5 \times 10^{-10} \mathrm{~m}$ obtained from the sum of the ionic radii (obtained from diffraction methods) ${ }^{34}{ }^{b} \Delta D / D^{\prime}{ }_{\mathrm{OF}}, \Delta D / D^{\prime \prime}{ }_{\mathrm{OF}}$, and $\Delta D / D^{\prime \prime \prime}{ }_{\mathrm{OF}}$ represent the relative deviations between $D$ (Table 1) and $D^{\prime}{ }_{\mathrm{OF}}, D^{\prime \prime}{ }_{\mathrm{OF}}$, and $D^{\prime \prime \prime}$ of values, respectively. ${ }^{c} a=3.8 \times 10^{-10} \mathrm{~m}$ estimated using MM2. ${ }^{35}{ }^{d} a=5.3 \times 10^{-10} \mathrm{~m}$ obtained from the sum of hydrated ionic radii (obtained from diffraction methods). ${ }^{34}{ }^{e}$ Relative deviations between $D$ extrapolated (Table 2) and the Nernst value (eq 6).

Table 4. Parameters Determined from Conductivity Data of $\mathrm{CuCl}_{2}$ Solutions at $298.15 \mathrm{~K}$ and $310.15 \mathrm{~K}$

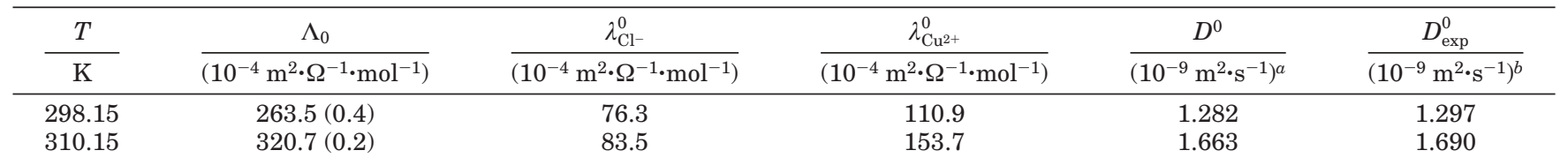

${ }^{a}$ These values have been calculated with eq $6 .{ }^{b}$ See Table 2.

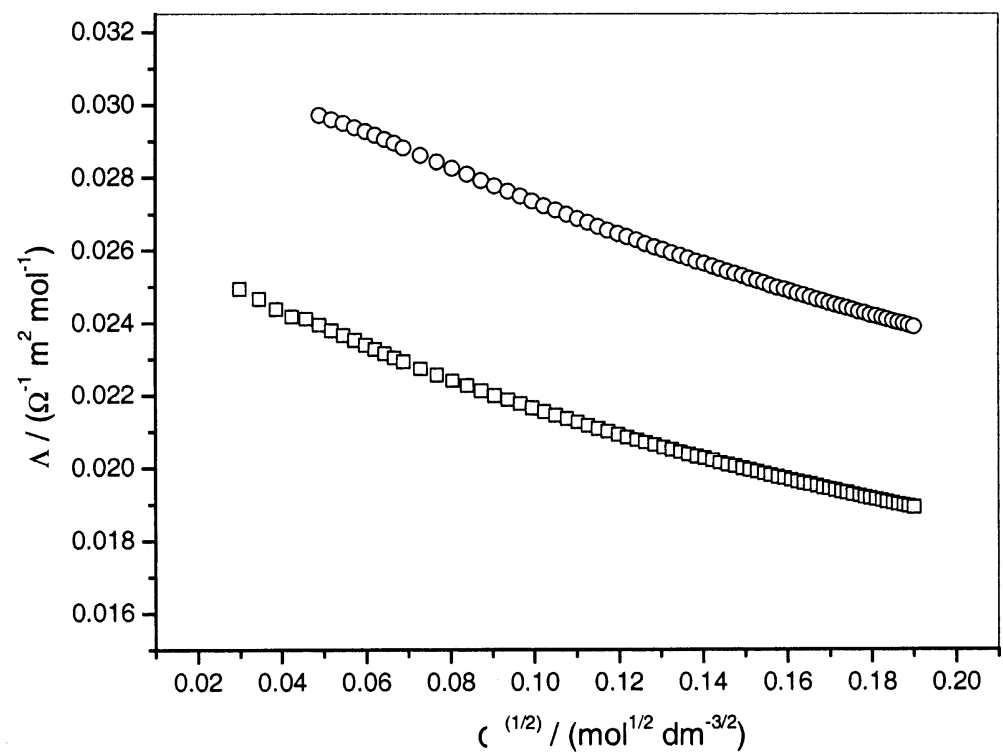

Figure 1. Molar conductivity $(\Lambda)$ versus square root of the molar copper(II) chloride concentration at different temperatures: $\square, 298.15$ $\mathrm{K} ; \mathrm{O}, 310.15 \mathrm{~K}$.

are given by

$$
\begin{aligned}
\Delta \overline{M^{\prime}} & =-\frac{c}{N_{\mathrm{A}}} \frac{\left(\left|z_{2}\right| \lambda_{1}^{0}-\left|z_{1}\right| \lambda_{2}^{0}\right)^{2}}{\left(\left|z_{1}\right| v_{1} \lambda_{2}^{0}+\left|z_{2}\right| v_{2} \lambda_{1}^{0}\right)^{2}} \frac{v_{1} v_{2}}{v_{1}+v_{2}} \frac{k}{6 \pi \eta_{0}(1+k a)} \\
\Delta \overline{M^{\prime \prime}} & =\frac{\left(v_{1}\left|z_{2}\right| \lambda_{1}^{0}+v_{2}\left|z_{1}\right| \lambda_{2}^{0}\right)^{2}}{\left(v_{1}\left|z_{1}\right| \lambda_{2}^{0}+v_{2}\left|z_{2}\right| \lambda_{1}^{0}\right)^{2}} \frac{1}{\left(v_{1}+v_{2}\right)^{2}} \frac{1}{N_{\mathrm{A}}^{2}} \frac{k^{4} \phi(k a)}{48 \pi^{2} \eta_{0}}
\end{aligned}
$$

where $\eta_{0}$ is the viscosity of the water in $\mathrm{N} \cdot \mathrm{s} \cdot \mathrm{m}^{-2} ; N_{\mathrm{A}}$ is the Avogadro's constant; $e_{0}$ is the proton charge in coulombs; $\nu_{1}$ and $\nu_{2}$ are the stoichiometric coefficients; $\lambda_{1}^{0}$ and $\lambda_{2}^{0}$ are the limiting molar conductivities of the cation and anion, respectively, in $\Omega^{-1} \cdot \mathrm{m}^{2} \cdot \mathrm{mol}^{-1} ; k$ is the "reciprocal average radius of ionic atmosphere" in $\mathrm{m}^{-1}$ (see, for example, ref $32) ; a$ is the mean distance of closest approach of ions in $\mathrm{m} ; \phi(k a)=\left|e^{2 k a} E_{i}(2 k a) /(1+k a)\right|$ has been tabulated by Harned and Owen, ${ }^{32}$ and the other letters represent wellknown quantities. ${ }^{32}$ In this equation, phenomena such as hydrolysis, ${ }^{29,30}$ complexation, and/or ion association ${ }^{33}$ are not taken into consideration. There is no direct method for measuring the ion size parameter $a$, "mean distance of closest approach" from the Debye-Hückel theory, but it may be estimated from the data of Marcus (Table 13 of ref 34 ) using two approximations. First, the $a$ values were estimated as the sum of the ionic radii $\left(R_{\text {ion }}\right)$ reported by Marcus. ${ }^{34}$ The $R_{\text {ion }}$ values were obtained as the difference between the mean internuclear distance of a monoatomic ion, or the central atoms of polyatomic ions, and the oxygen atom of a water molecule in its first hydration shells $\left(d_{\text {ion-water }}\right)$, and the half of the mean intermolecular distance between two water molecules in liquid water $\left(R_{\text {water }}\right)$. Briefly, $R_{\text {ion }}=\mathrm{d}_{\text {ion-water }}-R_{\text {water }}$ and $a=R_{\text {cation }}+R_{\text {anion. }}$ To account for the effect of the ion hydration shell on the $a$ values, a second approximation considers the sum of the

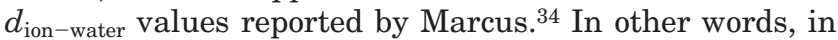
this approach the $a$ values are determined as $a=d_{\text {cation-water }}$ $+d_{\text {anion-water. }}$.

When parameter $a$ is estimated from molecular mechanic studies, ${ }^{35}$ using the molecular mechanics force field MM+ to minimize the energy of a system of ionic $\mathrm{CuCl}_{2}$ in a box 
of 1103 water molecules (number chosen to create a similar $\mathrm{CuCl}_{2}$ concentration to that of the experiments in the range of $0.05 \mathrm{M}$, see Appendix I in Supporting Information), we see that the calculated $a$ value of $3.7 \times 10^{-10} \mathrm{~m}$ is between those obtained by Marcus, ${ }^{34}$ pointing to some compression of the respective hydration shells (Table 3 ).

Comparing the calculated diffusion coefficients of $\mathrm{CuCl}_{2}$, $D_{\mathrm{OF}}$ (Table 3 ), using the three values of the parameter $a$ with the related experimental values at $298.15 \mathrm{~K}$ (Table 1), a reasonable agreement is observed between the experimental data and this model for $a=3.8 \times 10^{-10} \mathrm{~m}$ (deviations $\leq 3 \%$ ). The deviation between the limiting $D^{0}$ value calculated by extrapolating experimental data to $c$ $\rightarrow 0$ (Table 2) and the Nernst value (Table 3) is also acceptable $(0.08 \%)$. The decrease of the diffusion coefficient, when the concentration increases, may be interpreted on the basis of species resulting from the hydrolysis and complexation of this salt. From literature data, we may assume ${ }^{29}$ that $\mathrm{Cu}_{2}(\mathrm{OH})_{2}{ }^{2+}, \mathrm{Cu}_{3}(\mathrm{OH})_{4}{ }^{2+}, \ldots, \mathrm{Cu}_{n+1}(\mathrm{OH})_{2 n}{ }^{2+}$ are dominant in those circumstances. The linear BeerLambert plot and absence of change in shape of the visible spectrum suggested these species must have very similar spectral signatures. The eventual formation of ion pairs, increasing with concentration, may also contribute to the decrease of $D_{(\mathrm{CuCl} 2)}$ with concentration. In relation to the effect of temperature on diffusion, an increase in the experimental $D$ values was found at all copper chloride concentrations. Also, the decrease of the diffusion coefficient was obtained when the concentration increases. However, given the absence of the values of parameters for estimations of $D_{\mathrm{OF}}$, only the diffusion coefficient of copper chloride at infinitesimal concentration and the equivalent conductance of the copper ion were estimated.

From the following equation for analysis of the data, shown in Table 2, we estimated the diffusion coefficient of copper chloride at infinitesimal concentration as $D^{0}=1.690$ $\times 10^{-9} \mathrm{~m}^{2} \cdot \mathrm{s}^{-1}$ at $310.15 \mathrm{~K}$. To estimate $\lambda_{\mathrm{Cu}^{2+}}^{0}$, we may assume that the above $D^{0}$ value coincides with the Nernst value $^{26}$ from

$$
D^{0}=\frac{R T}{F^{2}} \frac{\left|Z_{\mathrm{Cu}^{2+}}\right|+\left|Z_{\mathrm{Cl}^{-}}\right|}{\left|Z_{\mathrm{Cu}^{2+}} Z_{\mathrm{Cl}^{-}}\right|} \frac{\lambda_{\mathrm{Cu}^{2+}}^{0} \lambda_{\mathrm{Cl}^{-}}^{0}}{\lambda_{\mathrm{Cu}^{2+}}^{0}\left|Z_{\mathrm{Cl}^{-}}\right|+\lambda_{\mathrm{Cl}^{-}}^{0}\left|Z_{\mathrm{Cu}^{2+}}\right|}
$$

where $Z_{\mathrm{Cu}^{2+}}$ and $Z_{\mathrm{Cl}^{-}}$represent the algebraic valences of a cation and of an anion, respectively. $\lambda_{\mathrm{Cl}^{-}}^{0}$ is the molar conductance of $\mathrm{Cl}^{-}$at infinitesimal concentration, estimated by using a polynomial equation fitted to experimental data from ref 36 (that is, $\lambda_{\mathrm{Cl}^{-}}^{0}=83.5 \times 10^{-4} \Omega^{-1}$. $\left.\mathrm{m}^{2} \cdot \mathrm{mol}^{-1}\right)$. Therefore, from eq 6 we have $\lambda_{\mathrm{Cu}^{2+}}^{0}=158.6 \times$ $10^{-4} \Omega^{-1} \cdot \mathrm{m}^{2} \cdot \mathrm{mol}^{-1}$ at $310.15 \mathrm{~K}$.

Figure 1 (data shown in Appendix II in Supporting Information) shows the molar conductivity of $\mathrm{CuCl}_{2}$ solutions (corrected for solvent conductance) at (298.15 and $310.15) \mathrm{K}$. The molar conductivity values at $298.15 \mathrm{~K}$ are in very close agreement with those reported in ref 37 . The molar conductivity data shows a linear relationship at concentrations below $6.4 \times 10^{-3} \mathrm{~mol} \cdot \mathrm{dm}^{-3}$ (at $298.15 \mathrm{~K}$ ) and $12.1 \times 10^{-3} \mathrm{~mol} \cdot \mathrm{dm}^{-3}$ (at $310.15 \mathrm{~K}$ ) with the square root of concentration. Such a relationship will enable us to calculate the molar conductivity at infinitesimal concentration of the $\mathrm{CuCl}_{2}$ solution $\left(\Lambda_{0}\right)$ according to the Kohlrauch equation. Table 4 shows molar conductivity at infinitesimal concentration of the $\mathrm{CuCl}_{2}$ solution $\left(\Lambda_{0}\right)$, limiting molar conductivity for copper ion $\left(\lambda_{0}^{+}\right)$and limiting diffusion coefficient $\left(D^{0}\right)$ at the two different temperatures. The limiting diffusion coefficients calculated from conductance and diffusion data are in close agreement.

\section{Supporting Information Available:}

Final configuration of the $\mathrm{Cu}^{2+}$ and $\mathrm{Cl}^{-}$ions in a cubic box and data for molar conductances of aqueous copper(II) solutions at $298.15 \mathrm{~K}$ and $310.15 \mathrm{~K}$. This material is available free of charge via the Internet at http://pubs.acs.org.

\section{Literature Cited}

(1) Taher, N. M.; Al Jabab, A. S. Galvanic corrosion behaviour of implant supra-structure dental alloys. Dent. Mater. 2003, 19, 5459.

(2) Reclaru, L.; Lerf, R.; Eschler, P. Y.; Blatter, A.; Meyer, J. M Pitting, crevice and galvanic corrosion of rex stainless-steel/CoCr orthopaedic implant material. Biomaterials 2002, 23, 3479-3485.

(3) Horasawa, N.; Takahashi, S.; Marek, M. Galvanic interaction between titanium and gallium alloy or dental amalgam. Dent. Mater. 1999, 15, 318-322.

(4) Grosgogeat, B.; Reclaru, L.; Lissac, M.; Dalard, F. Measurement and evaluation of galvanic corrosion between titanium/Ti6Al14V implants and dental alloys by electrochemical techniques and auger spectrometry. Biomaterials 1999, 20, 933-941.

(5) Venugopalan, R.; Lucas, L. C. Evaluation of restorative and implant alloys galvanically coupled to titanium. Dent. Mater. 1998, 14, 165-172.

(6) Reclaru, L.; Meyer, J. M. Study of corrosion between a titanium implant and dental alloys. J. Dent. 1994, 22, 159-168.

(7) Lobo, V. M. M. Handbook of Electrolyte Solutions; Elsevier: Amsterdam, 1990.

(8) Agar, J. N.; Lobo, V. M. M. Measurement of diffusion coefficients of electrolytes by a modified open-ended capillary method. $J$. Chem. Soc., Faraday Trans. 1975, I 71, 1659-1666.

(9) Lobo, V. M. M. Mutual diffusion coefficients in aqueous electrolyte solutions. Pure Appl. Chem. 1993, 65, 2613-2640.

(10) Lobo, V. M. M.; Ribeiro, A. C. F.; Verissimo, L. M. P. Diffusion coefficients in aqueous solutions of magnesium nitrate at $298 \mathrm{~K}$. Ber. Bunsen-Ges. Phys. Chem. 1994, 98, 205-208.

(11) Lobo, V. M. M.; Ribeiro, A. C. F.; Verissimo, L. M. P. Diffusion coefficients in aqueous solutions of beryllium sulfate at $298 \mathrm{~K}$. J. Chem. Eng. Data 1994, 39, 726-728.

(12) Lobo, V. M. M.; Ribeiro, A. C. F.; Valente, A. J. M. Célula de difusão condutimétrica de capilares abertos-uma análise do método. Corros. Prot. Mater. 1995, 14, 14-21.

(13) Lobo, V. M. M.; Ribeiro, A. C. F.; Andrade, S. G. C. S. Diffusion coefficients in aqueous solutions of divalent electrolytes. Ber Bunsen-Ges. Phys. Chem. 1995, 99, 713-720.

(14) Lobo, V. M. M.; Ribeiro, A. C. F.; Verissimo, L. M. P. Diffusion coefficients in aqueous solutions of potassium chloride at high and low concentrations. J. Mol. Liq. 1998, 78, 139-149.

(15) Ribeiro, A. C. F.; Lobo, V. M. M.; Natividade, J. J. S. Diffusion coefficients in aqueous solutions of potassium thiocyanate at 298.15 K. J. Mol. Liq. 2001, 94, 61-66.

(16) Ribeiro, A. C. F.; Lobo, V. M. M.; Azevedo, E. F. G.; Miguel, M. G.; Burrows, H. D. Diffusion coefficients of sodium dodecylsulfate in aqueous solutions and in aqueous solutions of sucrose. J. Mol. Liq. 2001, 94, 193-201.

(17) Ribeiro, A. C. F.; Lobo, V. M. M.; Azevedo, E. F. G. Diffusion coefficients of ammonium monovanadate in aqueous solutions at 298.15 K. J. Solution Chem. 2001, 30, 1111-1115.

(18) Ribeiro, A. C. F.; Lobo, V. M. M.; Natividade, J. J. S. Diffusion coefficients in aqueous solutions of cobalt chloride at $298.15 \mathrm{~K}$. J. Chem. Eng. Data 2002, 47, 539-541.

(19) Ribeiro, A. C. F.; Lobo, V. M. M.; Azevedo, E. F. G.; Miguel, M. G.; Burrows, H. D. Diffusion coefficients of sodium dodecylsulfate in aqueous solutions and in aqueous solutions of $\beta$-cyclodextrin. J. Mol. Liq. 2003, 102, 285-292.

(20) Lobo, V. M. M.; Valente, A. J. M.; Ribeiro, A. C. F. Differential mutual diffusion coefficients of electrolytes measured by the openended conductometric capillary cell: a review. In Focus on Chemistry and Biochemistry; Zaikov, G. E., Lobo, V. M. M., Guarrotxena, N., Eds.; Nova Science Publishers: New York, 2003.

(21) Valente, A. J. M.; Ribeiro, A. C. F.; Lobo, V. M. M.; Jiménez, A. Diffusion coefficients of lead(II) nitrate in nitric acid aqueous solutions at 298 K. J. Mol. Liq. 2004, 111, 33-38.

(22) Ribeiro, A. C. F.; Valente, A. J. M.; Lobo, V. M. M.; Azevedo, E. F. G.; Amado, A. M.; Costa, A. M. A.; Ramos, M. L.; Burrows, H. D. Interactions of vanadates with carbohydrates in aqueous solutions. J. Mol. Struct. 2004, 703, 93-101.

(23) Ribeiro, A. C. F.; Lobo, V. M. M.; Valente, A. J. M.; Azevedo, E. F. G.; Miguel, M. G.; Burrows, H. D. Transport properties of alkyltrimethylammonium bromide surfactants in aqueous solutions. Colloid Polym. Sci. 2004, 283, 277-283.

(24) Ribeiro, A. C. F.; Lobo, V. M. M.; Oliveira, R. C.; Burrows, H. D Azevedo, E. F. G.; Fangaia, S. I. G.; Nicolau, P. M. G.; Guerra, F. A. D. R. A. Diffusion coefficients of chromium chloride in aqueous solutions at 298.15 K and 303.15 K. J. Chem. Eng. Data 2005, $50,1014-1017$ 
1990 Journal of Chemical and Engineering Data, Vol. 50, No. 6, 2005

(25) Onsager, L.; Fuoss, R. M. Irreversible processes in electrolytes. diffusion. Conductance and viscous flow in arbitrary mixtures of strong electrolytes. J. Phys. Chem. 1932, 36, 2689-2778.

(26) Robinson, R. A.; Stokes, R. H. Electrolyte Solutions, 2nd ed.; Butterworth: London, 1959

(27) Lobo, V. M. M.; Ribeiro, A. C. F. The electrophoretic effect in electrolyte solutions. Port. Electrochim. Acta 1993, 11, 297-304.

(28) Lobo, V. M. M.; Ribeiro, A. C. F.; Andrade, S. G. C. S. Diffusion coefficients of 301 electrolytes in aqueous solutions from Onsager-Fuoss and Pikal theories. Port. Electrochim. Acta 1996 $14,45-124$.

(29) Baes, C. F., Jr.; Mesmer, R. E. The Hydrolysis of Cations; John Wiley and Sons: New York, 1976.

(30) Burguess, J. Metal Ions in Solution; John Wiley \& Sons: Chichester: Sussex, England, 1978.

(31) Barthel, J.; Feuerlein, F.; Neuder, R.; Wachter, R. Calibration of conductance cells at various temperatures. J. Solution Chem. 1980, 9, 209-219.

(32) Harned, H. S.; Owen, B. B. The Physical Chemistry of Electrolytic Solutions, 3rd ed.; Reinhold Pub. Corp: New York, 1964.

(33) Lobo, V. M. M.; Ribeiro, A. C. F. Ionic association: ion pairs. Port. Electrochim. Acta 1994, 12, 29-41.
(34) Marcus, Y. Ionic radii in aqueous solutions. Chem. Rev. 1988, 88, 1475-1498.

(35) HyperChem v6.03 software; Hypercube Inc.: 2000. MM+ molecular mechanics force field calculation using a Polak-Ribiere conjugated gradient algorithm for energy minimization in water with a final gradient of $0.05 \mathrm{kcal} / \mathrm{A} \mathrm{mol}$.

(36) Dobos, D. Electrochemical Data. A Handbook for Electrochemists in Industry and Universities; Elsevier: New York, 1975.

(37) Ellis, R. N.; Stokes, R. H.; Wright, A. C.; Spiro, M. Transference numbers and conductance in concentrated copper(II) chloride solutions at $25^{\circ} \mathrm{C}$. Aust. J. Chem. 1983, 36, 1913-1921.

Received for review June 6, 2005. Accepted August 2, 2005. Financial support from FCT, FEDER, POCTI (QUI/39593/2001) and POCI/AMB/55281/2004 is gratefully acknowledged. M.A.E. is thankful for "Consejería de Educación, Cultura y Deportes, Gobierno de Canarias", the postdoctoral grant that permitted him to stay at the University of Coimbra.

JE050220Y 